\title{
C-Reactive Protein versus Erythrocyte Sedimentation Rate: Implications Among Patients with No Known Inflammatory Conditions
}

\author{
Vanessa Alende-Castro, MD, Manuela Alonso-Sampedro, BSc, PhD, \\ Carmen Fernández-Merino, MD, PhD, Juan Sánchez-Castro, MD, \\ Bernardo Sopeña, MD, PhD, Francisco Gude, MD, PhD, and \\ Arturo Gonzalez-Quintela, $M D, P b D$
}

Background: Measurements of C-reactive protein (CRP) concentration and erythrocyte sedimentation rate (ESR) are frequently ordered jointly in clinical practice.

Aim: To investigate the factors associated with discordances between CRP concentration and ESR in adults.

Methods: We conducted a cross-sectional study of 1472 adults with no known inflammatory disorders (44.5\% male; median age, 52 years; range, 18-91 years), randomly selected from a municipality in Spain. The participants underwent simultaneous measurements of ESR, serum CRP, and interleukin-6 concentrations. Alcohol consumption, smoking, and physical activity were evaluated by questionnaire. Body mass index (BMI) measurement and metabolic syndrome criteria were available for all participants.

Results: Most ( $\mathrm{n}=1123,74.9 \%)$ of the participants showed normal CRP and ESR values. Sixty-nine (4.6\%) participants showed high CRP and ESR values. Seventy-two (4.8\%) participants showed a discordant pattern of high ESR and normal CRP values, which was associated with age after adjusting for sex, alcohol consumption, physical activity, BMI, and the presence of metabolic syndrome (odds ratio [0R], 1.052; 95\% CI, 1.034-1.071; $P<.001)$. A total of $208(13.8 \%)$ participants showed a discordant pattern of high CRP and normal ESR values, which was associated with BMI after adjusting for covariates $(0 R, 1.099 ; 95 \% \mathrm{CI}, 1.064-1.136 ; P<.001)$. BMI appeared to be the main determinant of serum CRP concentrations in this population. Serum interleukin- 6 concentrations were positively associated with the discordant pattern of high CRP and normal ESR values.

Conclusion: In this general adult population with no overt inflammatory disease, the discordant pattern of high ESR and normal CRP was associated with greater age, whereas the pattern of high CRP and normal ESR was associated with higher BMI. (J Am Board Fam Med 2021;34:974-983.)

Keywords: Age, Alcohol, Body Mass Index, C-Reactive Protein, Erythrocyte Sedimentation Rate, Inflammatory Disorders, Interleukin-6, Metabolic Syndrome, Obesity, Physical Exercise, Sex, Smoking

\section{Introduction}

Serum or plasma C-reactive protein (CRP) concentration and erythrocyte sedimentation rate

This article was externally peer reviewed.

Submitted 20 February 2021; revised 26 April 2021; accepted 27 April 2021.

From the Department of Internal Medicine, Complejo Hospitalario Universitario, University of Santiago de Compostela, Spain (VA-C, BS, AG-Q); Primary Care Center, A Estrada, Spain (CF-M, JS-C); Department of Clinical Epidemiology, Complejo Hospitalario Universitario, Santiago de Compostela, Spain (MA-S, FG).

Funding: The study was supported by a grant from the Carlos III Institute of Health (Instituto de Salud Carlos III, PI16/01404 and PI16/01395), the Spanish Network for Additive Disorders (Red de Trastornos Adictivos, RD16/ 0017/0018, Spanish Ministry of Health) the Spanish Network for Preventive Activity and Health Promotion Research in Primary Care (Red de Actividades Preventivas y de Promocion
(ESR) are employed in routine clinical practice as laboratory markers of systemic inflammation. CRP was first described in 1930 in a patient with pneumococcal pneumonia. ${ }^{1}$ It is synthesized by hepatocytes after stimulation by cytokines (particularly interleukin [IL]-6), which are released during infection and tissue inflammation. ${ }^{2-4}$ CRP plays a role in the host defense and displays both

de Salud en Atención Primaria, RD16/0007/0006), and the European Regional Development Fund (FEDER).

Conflict of interest: The authors declare that they have no conflict of interest.

Corresponding author: Dr. A. Gonzalez-Quintela, Department of Internal Medicine, Hospital Clínico Universitario, 15706 University of Santiago de Compostela, Spain, Tel: +34981 951265, Fax: +34981950501 (E-mail: arturo.gonzalez. quintela@sergas.es). 
inflammatory and anti-inflammatory actions. ${ }^{2,3}$ Serum CRP concentrations are elevated in a variety of inflammatory disorders of infectious and noninfectious causes, as well as in certain malignancies. ${ }^{5}$ The ESR was first described more than a century ago ${ }^{6}$ but is still widely employed. ${ }^{7-10}$ ESR is the rate (in $\mathrm{mm} / \mathrm{h}$ ) at which red blood cells develop aggregates ${ }^{11}$ and depends mostly on the concentration of circulating acute-phase proteins, specifically fibrinogen. ${ }^{8,11}$ Similar to CRP, the ESR can increase in a variety of inflammatory and neoplastic conditions. ${ }^{7-10}$

Measurements of CRP concentration and ESR are frequently ordered jointly in clinical practice ${ }^{12}$ and are intended to detect and monitor systemic inflammation; however, their results do not exactly correlate, and discordances can be present. ${ }^{12}$ The majority of previous studies that have investigated the agreement between CRP and ESR values have included selected samples of patients with specific inflammatory diseases. ${ }^{10,13-20}$ More general studies comparing ESR and CRP have included patients with various diseases in the hospital ${ }^{21-26}$ and primary care settings. ${ }^{27-29}$ In general, CRP and ESR have similar diagnostic accuracy assessing acute inflammation, ${ }^{10}$ though CRP tends to be more reliable for disease monitoring because CRP levels change faster than the ESR ${ }^{12,26,27}$ and are less affected by patient age. ${ }^{27,29}$ In patients with chronic inflammatory conditions, CRP and ESR offer similar information, ${ }^{10,13-15}$ though discordances can exist. ${ }^{16-20}$ To the best of our knowledge, no study has investigated the potential factors associated with disagreement between CRP and ESR results in unselected samples from general adult populations with no apparent inflammatory disease, which is an important issue because CRP and ESR can be routinely ordered among blood screening tests for individuals who are asymptomatic, mildly symptomatic, or with unspecific clinical manifestations. Moreover, determining the distribution of CRP concentrations compared with ESR in general populations is important for interpreting reference values. The present study aimed to add information to the factors associated with inflammatory marker elevation by investigating the discordance between abnormal CRP and ESR values in the general adult population. We also investigated the correlation between serum IL-6 concentrations and both ESR and CRP abnormalities.

\section{Methods}

\section{Study Population and Design}

This cross-sectional study was conducted in the municipality of A-Estrada (Spain), as reported elsewhere. ${ }^{30}$ An outline of the study (A-Estrada Glycation and Inflammation Study [AEGIS]) is also available at www.clinicaltrials.gov (code NCT01796184). Briefly, the study included an age-stratified sample ( $\mathrm{n}=1516)$ of the adult population from the municipality. Seventeen individuals were excluded from the study due to specific inflammatory diseases. Of the remainder, 1472 participants (44.5\% male; median age, 52 years; range, 18-91 years) underwent a simultaneous measurement of CRP and ESR (see below) and completed an interviewer-administered questionnaire at the primary care center. The study was approved by the Regional Ethics Committee (code 2010-315). We obtained written informed consent from all the participants.

\section{Assessment of Lifestyle Variables}

\section{Alcobol Consumption}

We evaluated the number of standard drinking units ${ }^{31}$ regularly consumed per week, totaling the number of glasses of wine ( 1 unit, approximately $10 \mathrm{~g}$ ), bottles of beer (1 unit, approximately $10 \mathrm{~g}$ ), and spirits (2 units, approximately $20 \mathrm{~g}$ ) consumed. Participants with an alcohol consumption of 1 to 13 units/week, 14 to 27 units/week, $\geq 28$ units/week were considered light, moderate, and heavy drinkers, respectively. The remainder, comprising alcohol abstainers and occasional alcohol drinkers, were grouped.

\section{Smoking}

We considered consumers of at least 1 cigarette per day to be smokers. Individuals who had quit smoking during the preceding year were still considered smokers, whereas those who had quit more than 1 year before the study were considered exsmokers.

\section{Physical Activity}

All study participants completed the freely available International Physical Activity Questionnaire (short version, https://sites.google.com/site/theipaq/home), which has been validated in Spain. ${ }^{32}$ The questionnaire allows for the calculation of metabolic equivalents of task and for the stratification of habitual physical activity as low, moderate, or high, ${ }^{33}$ as previously described. ${ }^{30}$ 


\section{Definition of Metabolic Abnormalities}

Body mass index (BMI) was calculated as weight (in $\mathrm{kg}$ ) divided by the square of height (in meters). Accordingly, we classified the participants as having normal weight $\left(<25 \mathrm{~kg} / \mathrm{m}^{2}\right)$, overweight (25 to $\left.30 \mathrm{~kg} / \mathrm{m}^{2}\right)$, or obesity $\left(>30 \mathrm{~kg} / \mathrm{m}^{2}\right)$. We considered the participants as having metabolic syndrome if they had at least 3 of the following Adult Treatment Panel III criteria ${ }^{34}$ : (1) abdominal obesity (waist circumference $>102 \mathrm{~cm}$ for men and $>88 \mathrm{~cm}$ for women); (2) hypertriglyceridemia (fasting serum triglycerides $\geq 150 \mathrm{mg} / \mathrm{dL}$ ); (3) low highdensity lipoprotein (HDL)-cholesterol levels (fasting HDL-cholesterol levels $<40 \mathrm{mg} / \mathrm{dL}$ for men and $<50 \mathrm{mg} / \mathrm{dL}$ for women); (4) increased blood pressure (arterial blood pressure $\geq 130 / \geq 85 \mathrm{mmHg}$ or current antihypertensive medication use); and (5) hyperglycemia (fasting serum glucose levels $\geq 110 \mathrm{mg} / \mathrm{dL}$ or current antidiabetic therapy).

\section{C-Reactive Protein Assay}

We measured wide-range CRP (wrCRP) concentrations in fresh serum samples using commercial latexenhanced immunoturbidimetry in an Advia 2400 Clinical Chemistry System (Siemens, Germany). Serum C-reactive protein (CRP) causes agglutination of the latex particles coated with antihuman C-reactive protein. The agglutination of the latex particles is proportional to the CRP concentration and can be measured by turbidimetry. The reference interval (normal values) for adults employing this method is $0-0.5 \mathrm{mg} / \mathrm{dL}(0-5 \mathrm{mg} / \mathrm{L})$. CRP measurements were available for 1499 participants.

\section{Erythrocyte Sedimentation Rate Assay}

We measured the ESR in blood drawn in vacuum tubes containing $\mathrm{K}_{3}$ EDTA (Becton Dickinson, USA) employing an automated TEST-1 device (Alifax, Italy). TEST-1 has been validated using the reference Westergren method following the International Council for Standardization in Hematology criteria. $^{35,36}$ The reference ESR values are $0-20 \mathrm{~mm} /$ $\mathrm{h}$ for men and $0-30 \mathrm{~mm} / \mathrm{h}$ for women. The ESR was available for 1472 participants, and their results in this population have been reported elsewhere. ${ }^{30}$

\section{Interleukin-6 Assay}

We measured IL-6 concentrations in fresh serum samples using a commercial chemiluminescent immunoassay (IMMULITE 2000 System, Siemens). The sensitivity limit for this method is $2.0 \mathrm{pg} / \mathrm{mL}$.
According to the manufacturer, in reference range study for IMMULITE 2000 IL-6 on serum samples collected from 60 healthy laboratory volunteers, the nonparametric lower $95 \%$ range was from nondetectable to $3.4 \mathrm{pg} / \mathrm{mL}$, and the absolute range was from nondetectable to $5.9 \mathrm{pg} / \mathrm{mL}$. Interleukin-6 measurements were available for 1499 participants. The distribution and factors associated with serum IL-6 concentrations in this population have been reported elsewhere. ${ }^{37}$

\section{Statistical Analyses}

We used the Mann-Whitney test to compare numeric variables, and the Jonckheere-Terpstra trend test compares the numeric variables in ordinal categories. We used Spearman's rank test to assess the correlation and employed linear regression for multivariate analysis of the factors associated with CRP concentrations. For that purpose, we $\log _{10}$-transformed the CRP values to normalize their distribution. For the logarithmic transformation, we attributed an arbitrary value of $0.001 \mathrm{mg} / \mathrm{dL}$ for cases with undetectable CRP $(\mathrm{n}=4)$. For the statistical calculations, we considered IL-6 concentrations below the detection level $(\mathrm{n}=742)$ as $2 \mathrm{ng} / \mathrm{mL}$. We defined groups were defined according to the normality or abnormality of CRP levels $(>0.5 \mathrm{mg} / \mathrm{dL}[5 \mathrm{mg} / \mathrm{L}])$ and ESR $(>20 \mathrm{~mm} / \mathrm{h}$ for men and $>30 \mathrm{~mm} / \mathrm{h}$ for women). We employed logistic regression for the multivariate analysis of factors associated with the pattern of discordance between CRP and ESR values. We forced variables into the equation in all the multivariate models.

\section{Results}

\section{Serum C-Reactive Protein Concentrations in the Population}

General and Demographic Data

A total of 283 (18.9\%; 95\% CI, 16.9-21.0\%) participants had high $(>0.5 \mathrm{mg} / \mathrm{dL}[>5 \mathrm{mg} / \mathrm{L}]) \mathrm{CRP}$ concentrations. A total of 111 (7.4\%) participants had CRP concentrations $>1 \mathrm{mg} / \mathrm{dL}(10 \mathrm{mg} / \mathrm{L})$. Only 12 (0.8\%) participants had CRP concentrations $>3 \mathrm{mg} / \mathrm{dL}(30 \mathrm{mg} / \mathrm{L})$. Serum CRP concentrations significantly increased with age in the univariate analyses (Table 1). However, the positive association between age and CRP concentrations was attenuated after adjusting for covariates (Table 2). Serum CRP concentrations were not significantly different in the men and women in either the univariate (Table 1 ) or multivariate analyses (Table 2 ). 
Table 1. C-Reactive Protein Concentrations According to Demographics, Lifestyle Factors, and Metabolic Abnormalities*

\begin{tabular}{|c|c|c|c|}
\hline Factor & $\mathrm{N}$ & CRP (mg/dL) & $P$ value \\
\hline \multicolumn{4}{|l|}{ Sex } \\
\hline Female & 830 & $0.14(0.04-0.42)$ & Reference \\
\hline Male & 669 & $0.13(0.04-0.33)$ & .186 \\
\hline \multicolumn{4}{|l|}{ Age (years) } \\
\hline $18-35$ & 295 & $0.09(0.03-0.33)$ & Reference \\
\hline$>35-50$ & 408 & $0.11(0.04-0.35)$ & .033 \\
\hline$>50-65$ & 388 & $0.17(0.06-0.39)$ & $<.001$ \\
\hline$>65$ & 408 & $0.18(0.06-0.47)$ & $<.001$ \\
\hline \multicolumn{4}{|l|}{ Alcohol consumption } \\
\hline Abstainers & 539 & $0.16(0.05-0.46)$ & Reference \\
\hline Light drinkers & 591 & $0.11(0.03-0.33)$ & $<.001$ \\
\hline Moderate drinkers & 239 & $0.15(0.04-0.37)$ & .146 \\
\hline Heavy drinkers & 130 & $0.17(0.08-0.43)$ & .363 \\
\hline \multicolumn{4}{|l|}{ Smoking } \\
\hline Never smokers & 820 & $0.15(0.05-0.41)$ & Reference \\
\hline Ex-smokers & 388 & $0.13(0.04-0.34)$ & .127 \\
\hline Current smokers & 291 & $0.13(0.04-0.36)$ & .183 \\
\hline \multicolumn{4}{|l|}{ Physical activity } \\
\hline Low & 583 & $0.16(0.05-0.46)$ & Reference \\
\hline Moderate & 548 & $0.14(0.04-0.36)$ & .017 \\
\hline High & 368 & $0.11(0.04-0.33)$ & .005 \\
\hline \multicolumn{4}{|l|}{ Body mass index } \\
\hline Normal weight & 421 & $0.06(0.02-0.17)$ & Reference \\
\hline Overweight & 567 & $0.13(0.05-0.36)$ & $<.001$ \\
\hline Obesity & 511 & $0.25(0.10-0.55)$ & $<.001$ \\
\hline \multicolumn{4}{|l|}{ Metabolic syndrome } \\
\hline No & 1191 & $0.11(0.04-0.33)$ & Reference \\
\hline Yes & 308 & $0.27(0.12-0.59)$ & $<.001$ \\
\hline
\end{tabular}

CRP, C-reactive protein.

${ }^{*}$ Data are medians and interquartile $\left(25^{\text {th }}-75^{\text {th }}\right.$ percentile $)$ ranges (in brackets). The normal range for serum CRP concentrations is $0-0.5 \mathrm{mg} / \mathrm{dL}(0-5 \mathrm{mg} / \mathrm{L})$.

\section{Lifestyle Factors}

Light alcohol consumption was negatively associated with CRP concentrations, with the light drinkers having lower CRP concentrations than the abstainers in the univariate analysis (Table 1). After adjusting for covariates, light alcohol drinking was still significantly and independently associated with lower CRP concentrations, and even moderate alcohol consumption tended to be associated with lower CRP concentrations (Table 2). Serum CRP concentrations were not significantly different in the smokers or ex-smokers than in the never smokers in the univariate analysis (Table 1). However, current smoking tended to be associated with higher CRP concentrations after adjusting for
Table 2. Multivariate Analysis. Linear Regression of C-Reactive Protein $\left(\log _{10}\right.$-Transformed) in Relation to Demographics, Lifestyle Factors, and Metabolic

Factors

\begin{tabular}{llc}
\hline Factor & Coefficient (SE) & $P$ value \\
\hline Sex (male) & & \\
$\quad$ Female & Reference & NA \\
Male & $-0.050(0.035)$ & .157 \\
Age (years) & $0.002(0.001)$ & .087 \\
Alcohol consumption & & \\
Abstainers & Reference & NA \\
Light drinkers & $-0.114(0.036)$ & .001 \\
Moderate drinkers & $-0.090(0.048)$ & .061 \\
Heavy drinkers & $0.013(0.062)$ & .829 \\
Smoking & & \\
Never smokers & Reference & NA \\
Ex-smokers & $-0.029(0.038)$ & .445 \\
Current smokers & $0.087(0.043)$ & .042 \\
Physical activity & & \\
Low & Reference & NA \\
Moderate & $-0.033(0.035)$ & .348 \\
High & $-0.014(0.040)$ & .725 \\
Body mass index $\left(\mathrm{kg} / \mathrm{m}^{2}\right)$ & $0.045(0.003)$ & $<.001$ \\
Metabolic syndrome & & .084 \\
No & Reference & $\mathrm{NA}$ \\
Yes & $0.073(0.042)$ & \\
Constant (intercept) & $-2.178(0.107)$ & \\
\hline
\end{tabular}

CRP, C-reactive protein; NA, not applicable; SE, standard error.

*For the logarithmic transformation, we attributed an arbitrary value of $0.001 \mathrm{mg} / \mathrm{dL}$ to patients with undetectable CRP $(\mathrm{n}=4)$.

${ }^{\dagger}$ All listed covariates were entered into the equation.

${ }^{\ddagger}$ Covariates explained $17.4 \%$ of the CRP variability $\left(\mathrm{R}^{2}, 0.174\right)$.

The body mass index explained $15.7 \%$ of the CRP variability.

covariates in the multivariate analyses (Table 2). In the univariate analyses, serum CRP concentrations were lower in the participants who engaged in moderate to high physical activity than those who engaged in low physical activity (Table 1). However, the association between physical activity and lower CRP concentrations was attenuated mainly after adjusting for covariates in the multivariate analyses (Table 2).

\section{Metabolic Factors}

Serum CRP concentrations were significantly higher in overweight and obese individuals than those with normal weight (Table 1). Moreover, there was a significant trend of increasing serum 
Figure 1. Boxplot of serum C-reactive protein concentrations in relation to the number of metabolic syndrome criteria. Outliers (values outside 1.5 times the interquartile range above the upper quartile and below the lower quartile) are not represented but are included in the analyses. $P$ value was obtained with the JonckheereTerpstra trend test.

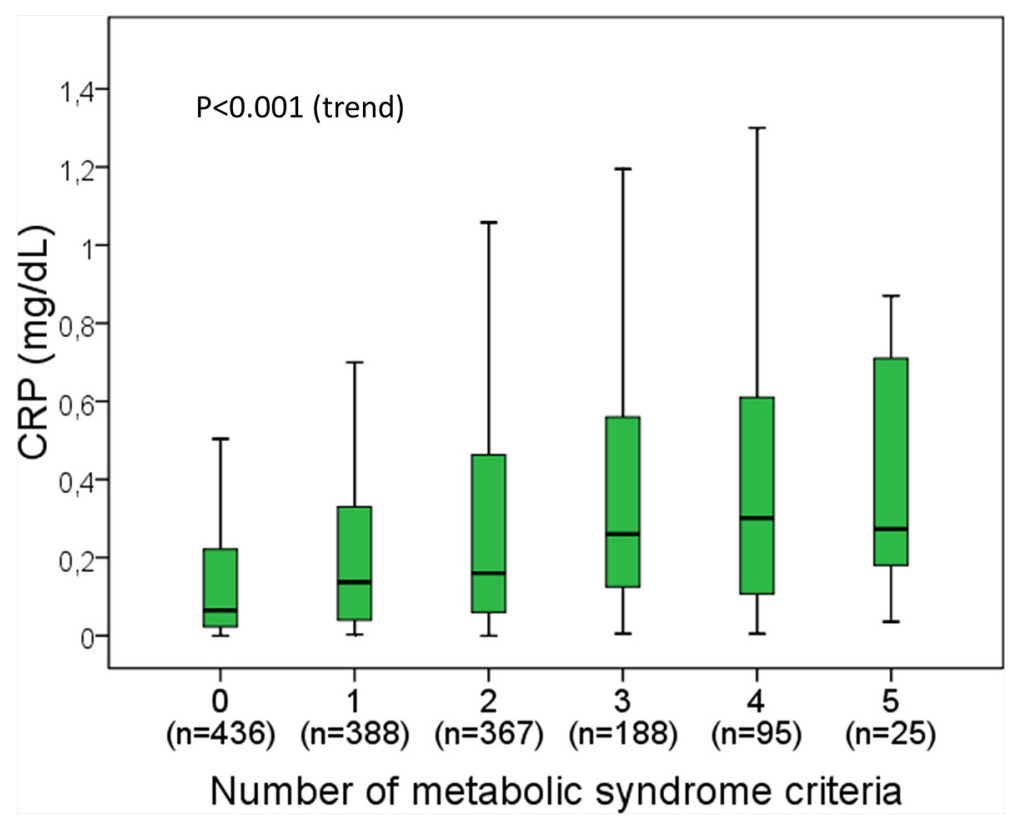

CRP concentrations with increasing BMI category $(P<.001)$. Median CRP concentrations were 4 times higher in the participants with obesity than in those with normal weight (Table 1). In the multivariate analyses, the positive association between $\mathrm{BMI}$ and CRP concentrations was still present after adjusting for age, sex, alcohol consumption, smoking, physical activity, and the presence of metabolic syndrome (Table 2). In the linear regression model, BMI explained $15.7 \%\left(\mathrm{R}^{2}=0.157\right)$ of the variation in serum CRP concentrations. The remaining covariates added only a minor explanation for the CRP variation (Table 2). Likewise, the presence of metabolic syndrome was positively associated with serum CRP concentrations in the univariate analysis (Table 1). Moreover, the participants who met any of the 5 metabolic syndrome criteria showed higher CRP concentrations than those who met none of the criteria $(P<.001$ in all cases, data not shown). Furthermore, serum CRP concentrations tended to increase in relation to the number of metabolic syndrome criteria per individual (Figure 1). However, the association between metabolic syndrome and CRP concentrations was attenuated by adjusting for covariates, particularly BMI (Table 2).

\section{Correlation and Agreement between C-Reactive Protein, Erythrocyte Sedimentation Rate, and Interleukin-6 Values}

The correlation between CRP concentrations and ESR values was statistically significant but not perfect $(\mathrm{r}=0.391 ; \mathrm{n}=1472 ; P<.001)$. Most $(\mathrm{n}=1123$, $74.9 \%)$ of the participants showed both normal CRP concentrations and normal ESR values. Sixtynine (4.6\%) participants showed both high CRP concentrations and high ESR values. A total of 72 (4.8\%) participants showed high ESR values and normal CRP concentrations, and 208 (13.8\%) showed high CRP concentrations and normal ESR values. Table 3 presents a comparison of the demographic, lifestyle, and metabolic factors among the categories of agreement and disagreement between the CRP and ESR values.

In the univariate analyses, participants with the pattern of high ESR and normal CRP showed significantly greater age, BMI, and presence of metabolic syndrome than in those from the reference category (normal CRP and normal ESR, Table 3). In the multivariate analysis (logistic regression), the pattern of high ESR and normal CRP was only significantly associated with age (Table 4). Among the 
Table 3. Comparison of Demographics, Lifestyle Factors, Metabolic Abnormalities among Categories of Agreement and Discordance between C-Reactive Protein and Erythrocyte Sedimentation Rate Values

\begin{tabular}{|c|c|c|c|c|}
\hline Factor & $\begin{array}{l}\text { Normal CRP Normal } \\
\text { ESR }(\mathrm{n}=1123)\end{array}$ & $\begin{array}{l}\text { High ESR Normal } \\
\text { CRP }(\mathrm{n}=72)\end{array}$ & $\begin{array}{l}\text { High CRP Normal } \\
\text { ESR }(\mathrm{n}=208)\end{array}$ & $\begin{array}{l}\text { High CRP High } \\
\text { ESR }(\mathrm{n}=69)\end{array}$ \\
\hline $\operatorname{Sex}(\mathrm{male})^{\mathrm{II}}$ & $514(45.8)$ & $30(41.7)$ & $78(37.5)^{*}$ & $33(47.8)$ \\
\hline Age (years) $)^{\pi}$ & $50(37-65)$ & $64(55-74)^{\ddagger}$ & $55(42-67)^{\dagger}$ & $64(49-76)^{\ddagger}$ \\
\hline Alcohol consumption (g/week) ${ }^{\pi}$ & $30(3-130)$ & $20(3-85)$ & $10(3-90)^{*}$ & $13(3-140)$ \\
\hline Smoking (current) ${ }^{\mathrm{II}}$ & $223(19.9)$ & $12(16.7)$ & $36(17.3)$ & $11(15.9)$ \\
\hline Physical activity (low) ${ }^{\mathrm{II}}$ & $411(36.6)$ & $31(43.1)$ & $91(43.8)$ & $40(58.0)^{\ddagger}$ \\
\hline Body mass index $\left(\mathrm{kg} / \mathrm{m}^{2}\right)^{\pi}$ & $27.2(23.9-30.6)$ & $28.1(25.4-31.7)^{*}$ & $30.0(26.2-33.7)^{\ddagger}$ & $32.0(27.0-35.6)^{\ddagger}$ \\
\hline Metabolic syndrome (yes) ${ }^{\mathrm{II}}$ & $185(16.5)$ & $24(33.3)^{\ddagger}$ & $68(32.7)^{\ddagger}$ & $23(33.3)^{\ddagger}$ \\
\hline Serum IL-6 $(\mathrm{pg} / \mathrm{mL})^{\pi}$ & $<2(<2-3.0)$ & $2.2(<2-4.1)$ & $3.0(<2-4.9)^{\ddagger}$ & $4.7(2.3-8.7)^{\ddagger}$ \\
\hline
\end{tabular}

CRP, C-reactive protein; ESR, erythrocyte sedimentation rate.

${ }^{*} P<.05 ;{ }^{\dagger} P<.01$; and ${ }^{\ddagger} P<.001$ compared with the reference category (individuals with normal CRP and normal ESR).

${ }^{\mathrm{f}}$ Data available for 1472 individuals.

${ }^{\S}$ High CRP is defined as $>0.5 \mathrm{mg} / \mathrm{dL}$ ( $>5 \mathrm{mg} / \mathrm{L}$ ); high ESR is defined as $>20 \mathrm{~mm} / \mathrm{h}$ for men and $>30 \mathrm{~mm} / \mathrm{h}$ for women.

${ }^{\mathrm{II}}$ Figures for sex, smoking, physical activity, and metabolic syndrome are absolute numbers and percentages (within parentheses).

"Figures for age, alcohol consumption, body mass index, and serum IL-6 are medians and interquartile ranges (within parentheses).

Table 4. Multivariate Analysis (Logistic Regression) of Factors Associated with Discordance between C-Reactive Protein and Erythrocyte Sedimentation Rate ${ }^{* \dagger}$

\begin{tabular}{lllll}
\hline & \multicolumn{2}{c}{ High ESR and normal CRP $(\mathrm{n}=72)$} & \multicolumn{2}{c}{ High CRP and normal ESR (n=208) } \\
\cline { 2 - 6 } Factor & OR $(95 \% \mathrm{CI})$ & $P$ value & OR (95\% CI) & $P$ value \\
\hline Sex (male) & $0.815(0.448-1.481)$ & .502 & $0.699(0.483-1.012)$ & .058 \\
Age (years) & $1.052(1.034-1.071)$ & $<.001$ & $0.998(0.988-1.008)$ & .695 \\
Body mass index $\left(\mathrm{kg} / \mathrm{m}^{2}\right)$ & $0.986(0.930-1.045)$ & .633 & $1.099(1.064-1.136)$ & $<.001$ \\
\hline
\end{tabular}

CI, confidence interval; CRP, C-reactive protein; ESR, erythrocyte sedimentation rate; OR, odds ratio.

${ }^{*}$ High CRP is defined as $>0.5 \mathrm{mg} / \mathrm{dL}(>5 \mathrm{mg} / \mathrm{L})$; high ESR is defined as $>20 \mathrm{~mm} / \mathrm{h}$ for men and $>30 \mathrm{~mm} / \mathrm{h}$ for women.

${ }^{\dagger} \mathrm{A}$ total of 1472 cases were entered into the equations. The odds ratio (adjusted for all listed variables and alcohol consumption, smoking, metabolic syndrome, and physical activity).

72 participants with high ESR and normal CRP, 35 $(48.6 \%)$ were older than 65 years.

In the univariate analyses, participants with the pattern of high CRP and normal ESR showed significantly greater age, a higher frequency of the female sex, higher BMI, and a greater presence of metabolic syndrome than those from the reference category (normal CRP and normal ESR), as well as lower alcohol consumption (Table 3). In the multivariate analysis (logistic regression), the pattern of high CRP and normal ESR was only significantly associated with BMI (Table 4). Among the 208 participants with high CRP and normal ESR, 174 (83.6\%) had overweight $(n=69)$ or obesity $(n=105)$.

The correlation between serum IL- 6 and CRP concentrations $(\mathrm{r}=0.280 ; \mathrm{n}=1499 ; P<.001)$ was stronger than that observed between serum IL-6 and ESR values $(\mathrm{r}=0.120 ; \mathrm{n}=1572 ; P<.001)$. Serum
IL-6 concentrations were increased $(>5.9 \mathrm{pg} / \mathrm{mL})$ in 69 of the 283 (24.4\%) participants with high CRP and in 76 of the $1216(6.3 \%)$ participants with low serum CRP concentrations. Serum IL-6 concentrations were higher among the participants with high CRP and normal ESR than those with high ESR and normal CRP $(P=.016$, Table 3$)$.

\section{Discussion}

The present study shows that increased CRP concentrations, with or without increased ESR occur in a sizeable proportion of adults with no apparent inflammatory disease. Determinations of serum CRP concentrations and ESR values are intended for similar purposes (diagnosis and monitoring of inflammatory diseases) but are distinct measurements influenced by different factors. Serum CRP 
concentrations are greatly influenced by BMI and related metabolic abnormalities, as shown in the present and previous studies, ${ }^{38-41}$, which suggest a state of low-grade systemic inflammation in people with overweight or obesity. ${ }^{40,42}$ Not surprisingly, increased serum CRP concentrations are a marker of cardiovascular risk. ${ }^{43}$ To a minor extent, CRP is negatively influenced by light-to-moderate alcohol consumption, in agreement with the anti-inflammatory effects of low-dose alcohol intake, as shown in this and previous studies. ${ }^{44} \mathrm{We}$ also observed higher CRP concentrations in smokers, which is consistent with previous studies. ${ }^{38,41}$ In our experience, the association between CRP concentrations and age and regular physical exercise reported in previous studies, ${ }^{45,46}$ was attenuated mainly after adjusting for covariates. In agreement with previous reports, ${ }^{38,39}$ sex had no significant influence on serum CRP concentrations. In contrast, the ESR is highly influenced by sex (being higher in women) and aging. ${ }^{30}$ To a minor extent, the ESR is positively influenced by BMI, the presence of metabolic syndrome, and smoking, whereas it is negatively influenced by light alcohol drinking and high regular physical activity. ${ }^{30}$

The present adult-population-based study, which included individuals with no apparent inflammatory disease that could cause increased CRP or ESR, shows that the finding of the discordant pattern of high ESR and normal CRP levels (present in $4.8 \%$ of individuals) is associated with older age, whereas high CRP and normal ESR (present in $13.8 \%$ of individuals) is associated with higher BMI, which was the main determinant of serum CRP concentrations in that population. Few studies have addressed the factors associated with CRP/ESR discordances. Costenbader et al studied 2065 patients from a hospital and found that rheumatoid arthritis and low albumin levels were associated with high CRP with low ESR (present in $1.5 \%$ of cases). In contrast, infection, renal failure, and low albumin levels were associated with the pattern of high ESR and low CRP (present in $2.6 \%$ of patients). ${ }^{21}$ In that study, CRP/ESR discordance was defined by results differing by 2 tertiles. $^{21}$ Colombet et al studied 5777 patients from a hospital and found that the pattern of high CRP and normal ESR was present in 5\% of cases, and that the pattern of high ESR and normal CRP was present in $28 \%$ of patients. ${ }^{22}$ A detailed study of 100 discordant cases showed that the pattern of high CRP and normal ESR was associated with active inflammatory diseases, whereas high ESR and normal CRP were associated with resolving inflammatory disease, ${ }^{22}$ probably due to the slower normalization of ESR in these cases. ${ }^{12}$ Feldman et al studied 2065 patients from a hospital and found that infections, myocardial infarction, and venous thromboembolism were associated with high CRP and low ESR (present in 6\% of cases), whereas connective tissue diseases and cerebrovascular diseases were associated with high ESR and low CRP (present in 6\% of patients). ${ }^{23}$ In that study, CRP/ESR discordance was defined by results differing by 2 or 3 quartiles. ${ }^{23}$ Hansson et al studied 607 individuals with CRP and ESR orders from general practitioners, mixing routine controls with patients with active infection or inflammatory disease or in their convalescence phase. ${ }^{29}$ In general, active infection and inflammatory disease were associated with high CRP and normal ESR (present in 16\% of patients), whereas resolving infection and an age $>50$ years were associated with high ESR and normal CRP (present in 5\% of cases). ${ }^{29}$ Osei-Bimpong et al studied a series of 295 individuals with CRP and ESR orders from general practitioners. The patients had no significant symptoms or detectable clinical signs and had not been hospitalized for at least 6 weeks before the study. However, the authors did not investigate the causes of discordance other than age. ${ }^{27}$ To the best of our knowledge, our study is the first to comprehensively investigate the factors associated with ESR/CRP discordance in a general adult population with no overt inflammatory disease.

In general, cytokines produced during the inflammation process stimulate tissues (particularly the liver) to produce reactants (such as CRP and fibrinogen), which in turn (particularly fibrinogen) increase the ESR. ${ }^{3,11}$ In this scenario, CRP and ESR can be viewed as second-hand and third-hand markers of inflammation, respectively. Despite this and the fact that they are more than a century old, these tests are still widely employed. ${ }^{10}$ However, direct measurement of serum cytokines is gaining attention as routine, first-hand markers of inflammation. Although serum IL-6 is not a mainstream laboratory determination yet, we investigated the relationship between IL-6 and ESR, CRP, and their discordances. Serum IL-6 concentrations showed a higher correlation with serum CRP concentrations than with ESR values. Serum IL-6 concentrations were, therefore, higher among the individuals with high CRP and normal ESR than among those with high ESR and normal CRP, which is consistent with IL-6 as the 
main driver of CRP synthesis. ${ }^{3,4}$ Moreover, this is consistent with an increase in serum IL-6 concentrations in individuals with obesity, as observed in the present series ${ }^{37}$ and previous studies. ${ }^{47}$ Furthermore, elevated CRP and IL-6 levels predict the onset of type 2 diabetes mellitus. ${ }^{47}$ However, future studies on inflammation markers in the general population should consider that IL-6 and CRP levels are not strictly correlated. Only a quarter of individuals with high CRP also display high IL-6 concentrations.

Our study has certain limitations that should be acknowledged, the first of which is its cross-sectional design, which has inherent temporal ambiguity, limiting any inference of causality. Lifestyle factors (alcohol consumption, smoking, and physical activity) were assessed by physician-administered questionnaires. Although multivariate analyses were performed, confounders could remain a limitation in observational studies. Commercial methods were used for laboratory determinations. Of note, laboratory methods have evolved, and absolute values in this study may not correlate with those reported in previous studies. We measured wide-range CRP (wrCRP), which shows good correlation with high-sensitivity CRP (hsCRP) and may be used as a reasonable routine assay to evaluate the cardiovascular risk in patients undergoing a routine annual checkup at a lower cost. $^{48}$ On the other hand, the random sampling, population basis, sample size, participation rate, and standardized methods could be considered strengths of the study. In terms of external validity, the conclusions can be applied only to similar populations of adults with no overt disease.

The results of the present study cannot serve to justify the systematic use of ESR and CRP in tandem, nor their systematic use in asymptomatic patients. However, it is a fact that the automatization of CRP and ESR measurements ${ }^{35,36}$ facilitates their widespread use in patients who are asymptomatic or mildly symptomatic and as a predictive marker (particularly CRP) of acute cardiovascular events including ischemic heart disease ${ }^{43}$ and stroke. ${ }^{49}$ Both ESR and CRP laboratory requests have increased in recent years in primary care, especially in some high-income countries. ${ }^{50}$ In many cases, the request as screening tests is not entirely justified, and the duplication (ESR and CRP) does not benefit. ${ }^{51}$ Moreover, mildly raised inflammatory markers in the context of nonspecific symptoms may be difficult to interpret and can lead to unnecessary further tests. ${ }^{52}$ Our results could help interpret laboratory results in that scenario. In otherwise healthy individuals, high ESR values and normal CRP concentrations are observed with increasing age, whereas CRP elevations and normal ESR values are observed with increasing BMI.

To see this article online, please go to: http://jabfm.org/content/ 34/5/974.full.

\section{References}

1. Tillett WS, Francis T. Serological reactions in pneumonia with a non-protein somatic fraction of pneumococcus. J Exp Med 1930;52:561-571.

2. Black S, Kushner I, Samols D. C-reactive protein. J Biol Chem 2004;279:48487-48490.

3. Marnell L, Mold C, Du Clos TW. C-reactive protein: Ligands, receptors and role in inflammation. Clin Immunol 2005;117:104-111.

4. Hunter CA, Jones SA. IL-6 as a keystone cytokine in health and disease. Nat Immunol 2015;16:448-457.

5. Landry A, Docherty P, Ouellette S, Cartier LJ. Causes and outcomes of markedly elevated C-reactive protein levels. Can Fam Physician 2017;63: e316-323.

6. Grzybowski A, Sak J. A short history of the discovery of the erythrocyte sedimentation rate. Int J Lab Hematol 2012;34:442-444.

7. Jou JM, Lewis SM, Briggs C, Lee SH, De La Salle $\mathrm{B}$, McFadden S, International Council for Standardization in Haematology. International Council for Standardization in Haematology. ICSH review of the measurement of the erythocyte sedimentation rate. Int $\mathrm{J}$ Lab Hematol 2011;33:125-132.

8. Sox HC, Jr, Liang MH. The erythrocyte sedimentation rate. Guidelines for rational use. Ann Intern Med 1986;104:515-523.

9. Brigden M. The erythrocyte sedimentation rate. Still a helpful test when used judiciously. Postgrad Med 1998;103:257-262.

10. Lapić I, Padoan A, Bozzato D, Plebani M. Erythrocyte sedimentation rate and C-reactive protein in acute inflammation. Am J Clin Pathol 2020;153:14-29.

11. Fabry TL. Mechanism of erythrocyte aggregation and sedimentation. Blood 1987;70:1572-1576.

12. Bray C, Bell LN, Liang H, et al. Erythrocyte sedimentation rate and C-reactive protein measurements and their relevance in clinical medicine. WMJ 2016;115:317-321.

13. Chan FLY, Lester S, Whittle SL, Hill CL. The utility of ESR, CRP and platelets in the diagnosis of GCA. PMR with a normal ESR at diagnosis was infrequent in our study compared with previous studies. BMC Rheumatol 2019;3:14. 
14. Nielung L, Christensen R, Danneskiold-Samsøe B, et al. Validity and agreement between the 28-Joint disease activity score based on C-reactive protein and erythrocyte sedimentation rate in patients with rheumatoid arthritis. Arthritis 2015;2015:401690.

15. Wells G, Becker JC, Teng J, et al. Validation of the 28-joint Disease Activity Score (DAS28) and European League Against Rheumatism response criteria based on C-reactive protein against disease progression in patients with rheumatoid arthritis, and comparison with the DAS28 based on erythrocyte sedimentation rate. Ann Rheum Dis 2009;68:954960.

16. Parikh M, Miller NR, Lee AG, et al. Prevalence of a normal C-reactive protein with an elevated erythrocyte sedimentation rate in biopsy-proven giant cell arteritis. Ophthalmology 2006;113:1842-1845.

17. Kermani TA, Schmidt J, Crowson CS, et al. Utility of erythrocyte sedimentation rate and C-reactive protein for the diagnosis of giant cell arteritis. Semin Arthritis Rheum 2012;41:866-871.

18. Fleischmann RM, van der Heijde D, Gardiner PV, Szumski A, Marshall L, Bananis E. DAS28-CRP and DAS28-ESR cut-offs for high disease activity in rheumatoid arthritis are not interchangeable. RMD Open 2017;3:e000382.

19. Solmaz D, Yildirim T, Avci O, Tomas N, Akar S. Performance characteristics of the simplified version of ankylosing spondylitis disease activity score (SASDAS). Clin Rheumatol 2016;35:1753-1758.

20. Cantini F, Salvarani C, Olivieri I, et al. Erythrocyte sedimentation rate and C-reactive protein in the evaluation of disease activity and severity in polymyalgia rheumatica: a prospective follow-up study. Semin Arthritis Rheum 2000;30:17-24.

21. Costenbader KH, Chibnik LB, Schur PH. Discordance between erythrocyte sedimentation rate and C-reactive protein measurements: clinical significance. Clin Exp Rheumatol 2007;25:746-749.

22. Colombet I, Pouchot J, Kronz V, et al. Agreement between erythrocyte sedimentation rate and C-reactive protein in hospital practice. Am J Med 2010;123:863.e7-13.

23. Feldman M, Aziz B, Kang GN, Opondo MA, Belz RK, Sellers C. C-reactive protein and erythrocyte sedimentation rate discordance: frequency and causes in adults. Transl Res 2013;161:37-43.

24. Katz PR, Gutman SI, Richman G, Karuza J, Bartholomew WR, Baum J. Erythrocyte sedimentation rate and C-reactive protein compared in the elderly. Clin Chem 1989;35:466-468.

25. Kenny RA, Saunders AP, Coll A, et al. A comparison of the erythrocyte sedimentation rate and serum C-reactive protein concentration in elderly patients. Age Ageing 1985;14:15-20.

26. Sbong S, Feldman M. Frequency and causes of Creactive protein and erythrocyte sedimentation rate disagreements in adults. Int J Rheum Dis 2015; 18:29-32.

27. Osei-Bimpong A, Meek JH, Lewis SM. ESR or CRP? A comparison of their clinical utility. Hematology 2007;12:353-357.

28. Dinant GJ, de Kock CA, van Wersch JW. Diagnostic value of C-reactive protein measurement does not justify replacement of the erythrocyte sedimentation rate in daily general practice. Eur J Clin Invest 1995;25:353-9.

29. Hansson LO, Carlsson I, Hansson E, Hovelius B, Svensson P, Tryding N. Measurement of C-reactive protein and the erythrocyte sedimentation rate in general practice. Scand J Prim Health Care 1995;13:39-45.

30. Alende-Castro V, Alonso-Sampedro M, VazquezTemprano N, et al. Factors influencing erythrocyte sedimentation rate in adults: new evidence for an old test. Medicine (Baltimore) 2019;98: e16816.

31. Gual A, Martos AR, Lligona A, Llopis JJ. Does the concept of a standard drink apply to viticultural societies?. Alcohol Alcohol 1999;34:153-160.

32. Román-Viñas BL, Ribas-Barba L, Ngo J. SerraMajem L. Validity of the international physical activity questionnaire in the Catalan population (Spain). Gac Sanit 2013;27:254-257.

33. Craig CL, Marshall AL, Sjöström $M$, et al. International physical activity questionnaire: $12-$ country reliability and validity. Med Sci Sports Exerc 2003;35:1381-1395.

34. Expert panel on detection, evaluation and treatment of high blood cholesterol in adults. Executive summary of third report of the National Cholesterol Education Program (NCEP) expert panel on detection, evaluation, and treatment of high blood cholesterol in adults (Adult Treatment Panel III). JAMA 2001;285:2486-2497.

35. Plebani M, De Toni S, Sanzari MC, Bernardi D, Stockreiter E. The TEST 1 automated system: a new method for measuring the erythrocyte sedimentation rate. Am J Clin Pathol 1998;110:334340.

36. Romero A, Muñoz M, Ramírez G. Length of sedimentation reaction in blood: a comparison of the test 1 ESR system with the ICSH reference method and the sedisystem 15. Clin Chem Lab Med 2003;41:232-237.

37. Alende-Castro V, Alonso-Sampedro M, Gude F, Gonzalez-Quintela A. Serum concentrations of interleukin-6 (IL-6) in the general adult population: possible implications for anti-IL-6 therapy in SARS-Cov-2 infection and IL-6-related diseases. J Investig Allergol Clin Immunol 2021;31:75-78.

38. Ahmadi-Abhari S, Luben RN, Wareham NJ, Khaw $\mathrm{K}-\mathrm{T}$. Distribution and determinants of C-reactive protein in the older adult population: European 
Prospective Investigation into Cancer-Norfolk study. Eur J Clin Invest 2013;43:899-911.

39. García-Lorda P, Bulló M, Balanzà R, Salas-Salvadó J. C-reactive protein, adiposity and cardiovascular risk factors in a Mediterranean population. Int $\mathrm{J}$ Obes (Lond) 2006;30:468-474.

40. Visser M, Bouter LM, McQuillan GM, Wener MH, Harris TB. Elevated C-reactive protein levels in overweight and obese adults. JAMA 1999;282:2131-2135.

41. Villegas R, Xiang YB, Cai H, et al. Lifestyle determinants of C-reactive protein in middle-aged, urban Chinese men. Nutr Metab Cardiovasc Dis 2012;22:223-230.

42. Hotamisligil GS. Inflammation and metabolic disorders. Nature 2006;444:860-867.

43. Jia RF, Li L, Li H, et al. Meta-analysis of C-reactive protein and risk of angina pectoris. Am J Cardiol 2020;125:1039-45.

44. Albert MA, Glynn RJ, Ridker PM. Alcohol consumption and plasma concentration of C-reactive protein. Circulation 2003;107:443-447.

45. Albert MA, Glynn RJ, Ridker PM. Effect of physical activity on serum C-reactive protein. Am J Cardiol 2004;93:221-225.

46. Hammonds TL, Gathright EC, Goldstein CM, Penn MS, Hughes W. Effects of exercise on C-reactive protein in healthy patients and in patients with heart disease: A meta-analysis. Heart Lung 2016;45:273-382.

47. Pradhan AD, Manson JE, Rifai N, Buring JE, Ridker PM. C-reactive protein, interleukin 6, and risk of developing type 2 diabetes mellitus. JAMA 2001;286:327-334.

48. Ziv-Baran T, Shenhar-Tsarfaty S, Etz-Hadar I, et al. The ability of the wide range CRP assay to classify individuals with low grade inflammation into cardiovascular risk groups. Clin Chim Acta 2017;471:185-90.

49. Evans CR, Long DL, Howard G, et al. C-reactive protein and stroke risk in blacks and whites: The REasons for Geographic And Racial Differences in Stroke cohort. Am Heart J 2019;217:94-100.

50. O'Sullivan JW, Stevens S, Hobbs FDR, et al. Temporal trends in use of tests in UK primary care, 2000-15: retrospective analysis of 250 million tests. BMJ 2018;363:k4666.

51. Watson J, Jones HE, Banks J, Whiting P, Salisbury C, Hamilton W. Use of multiple inflammatory marker tests in primary care: using Clinical Practice Research Datalink to evaluate accuracy. Br J Gen Pract 2019;69:e462-e469.

52. Watson J, de Salis I, Hamilton W, Salisbury C. 'I'm fishing really'-inflammatory marker testing in primary care: a qualitative study. Br J Gen Pract 2016;66:e200-6. 